\title{
Spontaneous atlantoaxial subluxation: an unusual presenting manifestation of Reiter's syndrome
}

\author{
R D MELSOM, ${ }^{1}$ J C BENJAMIN ${ }^{2}$ AND C G BARNES \\ From the Departments of ${ }^{1}$ Rheumatology and ${ }^{2}$ Neurosurgery, The London Hospital, Whitechapel, Londo
}

SUMMARY A male Sikh presented with spontaneous neck pain. Plain cervical radiography showed gross atlantoaxial subluxation (AAS). Computed tomography showed soft tissue anteriơ to a subluxed odontoid peg. A diagnosis of atlantoaxial tuberculosis was considerec Confirmation of this would have required a trans-oral anterior cervical biopsy. Despite the paucity of other rheumatic symptoms a diagnosis of Reiter's syndrome with spondylitis was made, and the only surgical procedure required was posterior fusion of $\mathrm{C} 1$ and $\mathrm{C} 2$, with resultan spinal stability and pain relief. This is the first report of Reiter's syndrome presenting with AA

Key words: seronegative spondyloarthropathy.

Spontaneous atlantoaxial subluxation (AAS), a serious complication of rheumatic disease, is seen most frequently in rheumatoid arthritis, psoriatic arthritis, and ankylosing spondylitis. In one study AAS was reported with a prevalence of 189 in 1000 patients with rheumatoid arthritis admitted to hospital. ${ }^{1}$ In another study nine cases of AAS were found in 21 patients with psoriatic spondylitis, who were themselves identified from 87 patients with psoriatic arthritis. ${ }^{2}$ When about 100 patients with ankylosing spondylitis were reviewed 17 cases of AAS were noted. ${ }^{1}$ In addition, there are three isolated reports of AAS in Reiter's syndrome, ${ }^{134}$ and one study in which two patients with AAS were identified from 145 consecutive cases of Reiter's syndrome. ${ }^{5}$ Atlantoaxial subluxation has not previously been reported as a presenting manifestation of Reiter's syndrome.

\section{Case report}

A 30 year old Sikh, born in India but resident in the UK for 13 years, presented with a three week history of acute continuous neck pain without

Accepted for publication 14 July 1988.

Correspondence to Dr R D Melsom, Department of Rheumatology, The London Hospital, Whitechapel, London E1 1BB. preceding trauma. There were no neurologic symptoms and no history of psoriasis. Initially ho denied any other relevant information but subse quently recalled an episode of urethritis occurring six years previously while revisiting India, ang requiring parenteral antibiotics. Immediately afters wards he had experienced an episode of neck, low back, and left ankle pain. The neck pain dis: appeared completely over a few weeks as did the ankle pain, leaving only persistent mild low back pain. Until the recent episode of neck pain he had neither sought medical advice nor had treatment fog any of these rheumatological symptoms. On examination, neck movements were reduced ang painful. Lumbosacral and thoracic spine movement was reduced but pain free. Chest expansion was $\mathrm{cm}$. Neurological examination was normal.

His erythrocyte sedimentation rate was $60 \mathrm{~mm} / \mathrm{h}$ (Westergren). Haematology, biochemistry, serot ogy, urine culture for tuberculosis, chest radi@o graphy, and Mantoux test were negative or normap He was B27 positive. Plain cervical radiographs showed $10 \mathrm{~mm}$ of AAS on extension, increasing to $15 \mathrm{~mm}$ on flexion. Computed tomography (CT) of the cervical spine showed AAS, an eroded odontoid peg compressing the theca and soft tissue anterior the peg (Figs 1a and b). Cervical myelography showed a distorted column of contrast at $\mathrm{C} 1$ to 


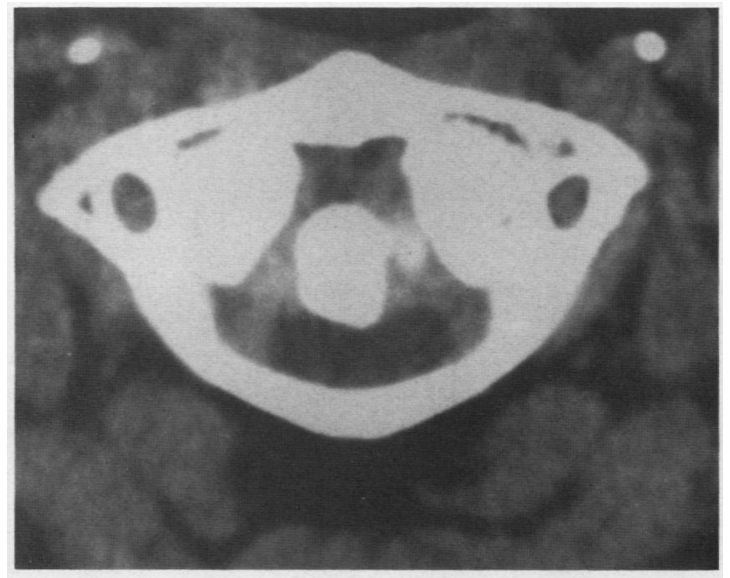

Fig. 1a

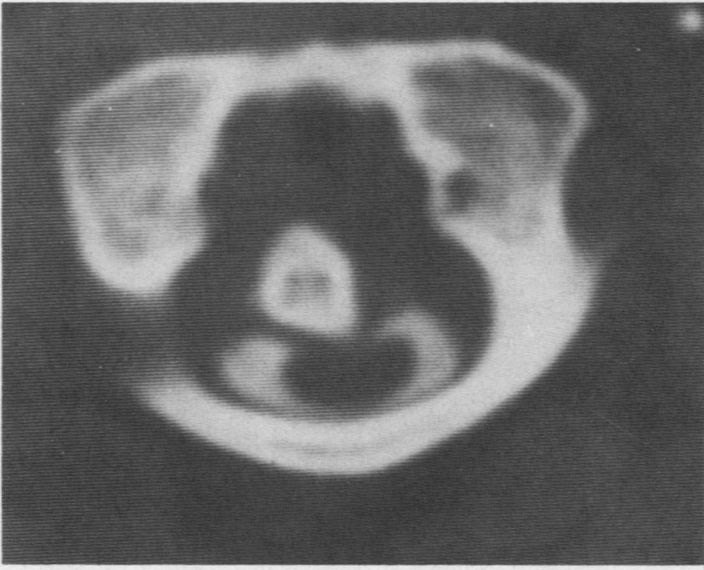

Fig. 1b

Fig. 1 (a) Computed tomogram at $\mathrm{Cl}$ without contrast; soft tissue is seen around the subluxed odontoid peg. The latter is compressing the theca. (b) Computed myelotomogram at C1; again the subluxed odontoid peg is seen to compress the dura which is now outlined by radio-opaque contrast medium.

(Fig. 2). Plain radiography demonstrated asymmetrical lumbar syndesmophytes and bilateral sacroiliitis. Joint space loss and erosions were evident at the left subtalar, mid-tarsal, and first toe interphalangeal joints.

He was treated initially with a collar. Subsequently, a posterior cervical fusion was performed; two laterally placed Harrington rods were attached by hooks superiorly to the atlas and inferiorly to $\mathrm{C} 2$. Iliac crest cancellous bone was then

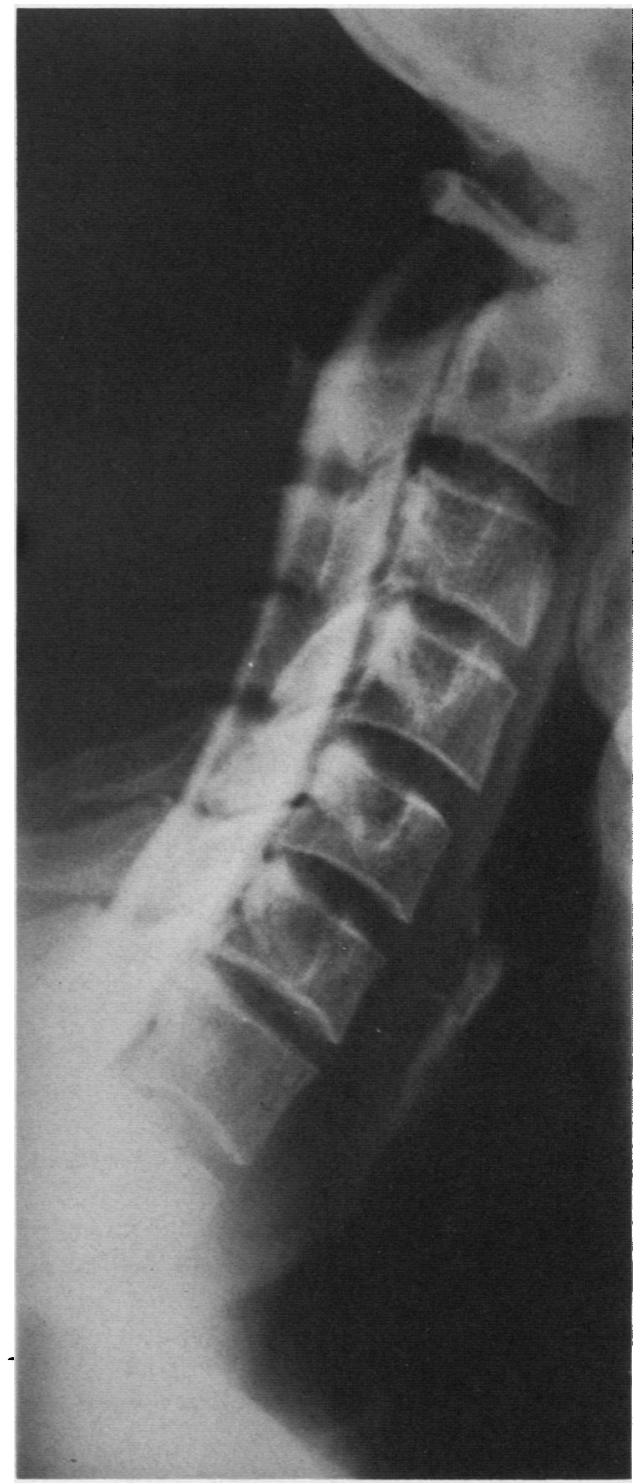

Fig. 2 Lateral cervical myelogram showing a column of radio-opaque contrast distorted at the level of $\mathrm{Cl}$ to $\mathrm{C2}$ by atlantoaxial subluxation.

packed between the two vertebrae. After the operation his neck pain resolved.

\section{Discussion}

Lifeso, in 1987, described 12 patients from Saudi Arabia with atlantoaxial tuberculosis. ${ }^{6}$ Fifteen additional sites of tuberculous involvement were 
identified in these patients; seven were musculoskeletal, three soft tissue, and five spinal. Features shared by those 12 patients and the patient reported here included neck pain and AAS at presentation, Asian origin, musculoskeletal and spinal involvement elsewhere, a raised erythrocyte sedimentation rate, and absence of features of tuberculosis on chest radiograph. Also, in the patient reported here CT showed material which could have been tuberculous around the subluxed odontoid. Thus, initially, tuberculous AAS was considered to be the most likely diagnosis in the patient described here. Confirmation of this diagnosis would have required a trans-oral approach to the odontoid peg to obtain involved tissue. Indeed, the report from Saudi Arabia advocated a trans-oral approach for both diagnosis and decompression of the spinal cord, followed by halo traction and, later, a posterior fusion of $\mathrm{C} 1$ and $\mathrm{C} 2$ for patients who had the degree of AAS caused by tuberculosis seen in the patient described here.

The patient reported here, however, differed in two respects from those described by Lifeso: he was negative on Mantoux testing and CT showed no evidence of a retropharyngeal abscess, whereas all 12 of the Saudi Arabian patients were Mantoux positive and 10 had retropharyngeal abscesses. Furthermore, in this patient there was much in favour of a diagnosis of Reiter's syndrome despite the paucity of recent rheumatological symptoms other than neck pain. Six years previously there had been an episode of urethritis and arthritis. Conjunctivitis had not been noticed, but eye involvement may be absent or subclinical in Reiter's syndrome. ${ }^{4} 7$ There had been persistent, if mild, lumbosacral pain with reduced, albeit pain free, spinal movement. ${ }^{7}$ There was radiological evidence of asymmetrical erosive joint disease in the legs but not the arms, ${ }^{7}$ asymmetrical lumbosacral syndesmophyte formation, ${ }^{3}$ and bilateral sacroiliitis. ${ }^{78}$ Furthermore, the patient was found to be positive for the HLA-B27 antigen, which is found in only $5 \%$ of the northentm Indian population. ${ }^{9}$

The diagnosis of Reiter's syndrome thus seemed secure. The possibility remained that this patient had Reiter's syndrome and tuberculous AAS Although AAS is a rare occurrence in Reiter $\frac{5}{5}$. syndrome compared with rheumatoid arthritis an psoriatic arthritis, ${ }^{12}$ it has been reported on five separate occasions previously. ${ }^{1345}$ Therefore it w\$ felt that the AAS was secondary to Reiter's syndrome and that complex surgery merely to exclude tuberculosis was not justified. The indicato tions and possible advantages of the anterior and posterior surgical approaches to $\mathrm{C} 1$ and $\mathrm{C} 2$ in the treatment of AAS in rheumatoid arthritis have beets reviewed elsewhere. ${ }^{10}$ In this case anterior decomin pression was not considered necessary as there wer no signs of spinal cord compression. A posteriof fusion of $\mathrm{C} 1$ and $\mathrm{C} 2$ was performed with complete relief of neck pain.

\section{References}

1 Sharp J, Purser D W. Spontaneous atlanto-axial dislocation an ankylosing spondylitis and rheumatoid arthritis. Ann Rheu Dis 1961; 20: 47-77.

2 Killebrew K, Gold R H, Sholkoff S D. Psoriatic spondfitt Radiology 1973; 108: 9-16.

3 Santaverta S, Slatis P, Sandelin J, Lindqvist C, Konttinen Atlanto-axial subluxation in patients with seronegative dylarthritis. Rheumatol Int 1987; 7: 43-6.

4 Latchaw R E, Meyer G W. Reiter's disease with atlanto-axio subluxation. Radiology 1978; 126: 303-4.

5 Moilanen A, Yli-Kerrtula U, Vilppula A. Cervical spin involvement in Reiter's syndrome. ROFO 1984; 141: 84-7.

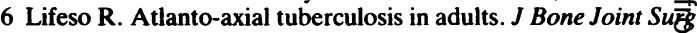
[Am] 1987; 69: 183-7.

7 Ford D K. Reiter's syndrome. Bull Rheum Dis 1970; 29 588-91.

8 Dirheimer Y. The craniovertebral region in chronic inflammatory rheumatic diseases. Berlin, Heidelberg, and New Yor Springer, 1977: 132

9 Aizawa M. HLA in Asia-Oceania 1986. Proceedings of the thi Asia-Oceania histocompatibility workshop conference. Japam. Hokkaido University Press, 1986: 1086.

10 King T T. Rheumatoid subluxations of the cervical spine. An Rheum Dis 1985; 44: 807-8. 